Departamento de Historia

Universidad de Santiago de Chile

Revista de Historia Social

y de las Mentalidades

Volumen 25, $\mathrm{N}^{\circ} 2,2021: 127-162$

Issn Online: 0719-4749

\title{
EL MENSAJE COTIDIANO DEL MUNDO: LAS AGENCIAS DE NOTICIAS INTERNACIONALES Y LA PRENSA COMUNISTA CHILENA DURANTE LA SEGUNDA GUERRA MUNDIAL*
}

\author{
THE WORLD'S DAILY MESSAGE: INTERNATIONAL NEWS AGENCIES AND THE \\ CHILEAN COMMUNIST PRESS DURING WORLD WAR II
}

\author{
DR. ALFONSO SALGADO MUÑOZ** \\ Universidad Diego Portales \\ Santiago, Chile \\ Email: as3918@columbia.edu \\ Id-ORCID: 0000-0001-6649-4291
}

\begin{abstract}
RESUMEN
Este artículo analiza las relaciones entre las empresas periodísticas del Partido Comunista de Chile y las agencias internacionales de noticias durante la Segunda Guerra Mundial. En base a un análisis de Frente Popular y El Siglo, y a documentación de diversos archivos, concluimos que los comunistas chilenos hicieron ingentes esfuerzos por proveerse de información noticiosa proveniente del exterior, estableciendo vínculos con distintas agencias, que tenían intereses y objetivos disímiles, entre las que destacan las estadounidenses United Press y Associated Press,

la alemana Transocean y la soviética TASS/ SUPress. Ahora bien, la dificultad para proveerse una cantidad sustantiva de información noticiosa ideológicamente confiable los obligó a utilizar
\end{abstract}

\begin{abstract}
This article analyses the relationship between international news agencies and the media companies of the Communist Party of Chile during World War II. Based on an analysis of Frente Popular and El Siglo and documentary evidence from some archives, I argue that Chilean Communists made significant efforts to provide news coming from abroad and established links with several news services, whose goals and interests differed, among which the American agencies United Press and Associated Press, the German agency Transocean, and the Soviet agency TASS played a prominent role. Nevertheless, the difficulties of obtaining a substantial amount of news from ideologically reliable sources forced them to depend in large
\end{abstract}

* $\quad$ Recibido: 3 de marzo de 2021; Aceptado: 11 de mayo de 2021.

** Este artículo de investigación es producto del Proyecto Postdoctorado Fondecyt $N^{\circ} 3190080$ : "Prensa de izquierda y gestión empresarial en Chile". 
de manera instrumental la mayor parte de estas fuentes.

Palabras clave: Comunismo; prensa; agencias de noticias; Segunda Guerra Mundial part of US news agencies and to use these and other sources of information instrumentally.

Keywords: Communism; Press; News Agencies; World War II

Cómo citar: Salgado M., Alfonso. (2021). "El mensaje cotidiano del mundo: Las agencias de noticias internacionales y la prensa comunista chilena durante la Segunda Guerra Mundial". Revista Historia Social $y$ de las Mentalidades, 25(2), 127-162. https://doi.org/10.35588/rhsm.v25i2.4815

\section{INTRODUCCIÓN}

"Hitler inició ataque a la patria socialista". Con este titular, en grandes letras mayúsculas, el periódico comunista El Siglo anunció el comienzo de la Operación Barbarroja en su edición del 22 de junio de 1941. El titular estaba acompañado de una gran cantidad de cables informativos. El primero, con carácter de urgente, provenía de Berlín y llevaba la firma "T.O.", acrónimo de la agencia de noticias alemana Transocean. Los cables restantes provenían de Londres y Nueva York, y venían firmados todos ellos por "A.P.", la prestigiosa agencia estadounidense Associated Press (El Siglo, "Hitler inició ataque" 5). La noticia del ataque alemán contra la Unión Soviética había llegado a Chile solo unas pocas horas antes, en la madrugada, cuando la edición del periódico que saldría a circulación a primera hora de la mañana estaba ya en manos de los linotipistas. Volodia Teitelboim, quien estaba encargado de la sección internacional del periódico, recuerda haber estado en el Teatro Imperio cuando se enteró de la noticia, y haber tomado la decisión de dirigirse inmediatamente a la redacción. Junto con el director del periódico, Ricardo Fonseca, y otros periodistas que llegaron a la redacción, se dieron a la tarea de rehacer la portada y escribir una nueva página editorial, intentando orientar a un público fiel, que admiraba a la Unión Soviética y temía por su destino (Teitelboim, Un hombre 110; Partido Comunista de Chile 122; Millas 273-274).

El sorpresivo ataque de Alemania contra la patria socialista forzó a los comunistas chilenos no solo a adoptar un drástico giro en su política -de denunciar la Segunda Guerra Mundial como un conflicto imperialista y abogar por la neutralidad, pasaron a definirla como una guerra contra el fascismo y llamaron a romper relaciones diplomáticas con las potencias del Eje- sino también a repensar su estrategia comunicacional. Los encargados de El Siglo debieron dejar de utilizar los servicios informativos de Transocean, un servicio financiado por la Alemania nazi, que habían utilizado con cierta frecuencia en años 
anteriores, y brindarle más espacio a las informaciones de SUPress, una agencia de noticias que operaba Komintern y que se nutría de información recopilada por la agencia soviética TASS. ${ }^{1} \mathrm{El}$ interés del público en los acontecimientos, y en conocer la versión soviética de estos, parecen haber contribuido al aumento del tiraje de El Siglo, que, tras la invasión alemana, empezó a vender 6.000 ejemplares más de lo habitual, aumento que, según los encargados del periódico, "se explica por la calidad de nuestras informaciones internacionales, muchas de ellas enviadas exclusivamente desde Moscú" (El Siglo, "En 6 mil ejemplares" 1). El avance alemán interrumpió la comunicación entre los comunistas chilenos y la patria socialista un tiempo después, por lo que los encargados de El Siglo debieron enviar a uno de sus trabajadores a Buenos Aires a establecer "contactos para recibir los servicios informativos soviéticos y con ellos las crónicas de sus corresponsales de guerra" (Millas 273; cfr. Corvalán).

Este artículo se pregunta por la circulación global de la información noticiosa durante los años de la Segunda Guerra Mundial. Aquí se estudia, con cierto nivel de detalle, las relaciones entre las empresas periodísticas de los comunistas chilenos y las agencias internacionales de noticias. El análisis se centra en Frente Popular (publicado entre 1936 y 1940) y El Siglo (cuya primera época va de 1940 a 1948), órganos oficiales del Partido Comunista de Chile (PCCh). ${ }^{2}$ Sostenemos, a modo de hipótesis, que las empresas periodísticas del PCCh hicieron ingentes esfuerzos por proveerse de información proveniente del exterior y responder a la demanda de un público lector interesado en el acontecer internacional. A diferencia de la mayoría de los periódicos chilenos de la época, que se contentaron con proveerse de los servicios cablegráficos de una sola fuente, Frente Popular y El Siglo establecieron vínculos con distintas agencias internacionales, que tenían intereses y objetivos disímiles, incluso antagónicos, entre las que destacan las agencias estadounidenses United Press y Associated

1 Los periódicos y fuentes chilenas de la época hablan de Supress, SUPress o SUPRESS (al parecer, un acrónimo de Soviet Union Press) y no de TASS (Telegrafnoye Agentstvo Sovyetskoyo Soyouza). A diferencia de TASS, SUPress parece haber formado parte de Komintern. Ahora bien, dado que su sede central estaba en Moscú y que difundía propaganda sobre la vida en la Unión Soviética, muy similar a la propaganda que difundía TASS en otros países, hemos decidido considerarla una agencia propiamente soviética. Hay escasas referencias a SUPress en la literatura secundaria, incluso en la que analiza la historia de los servicios informativos soviéticos, y la relación entre Supress y TASS no es del todo clara. Ahora bien, para simplificar, en este artículo hablaremos de TASS/SUPress, analizándolas conjuntamente, e incluiremos también bajo dicha categoría informaciones publicadas bajo el acrónimo "S.P.B.", que probablemente provenían de Sovinformburó, tras la disolución de Komintern en 1943.

2 La literatura sobre la prensa comunista en Chile no es particularmente abundante, pero ha tendido a crecer en los últimos años (Loyola; Rojas; Rivera y Salgado; Salgado). 
Press, la agencia alemana Transocean y la agencia soviética TASS/SUPress. Ahora bien, la diversidad de la procedencia de la información noticiosa publicada en la prensa comunista chilena no debe tampoco exagerarse. La dificultad para proveerse una cantidad sustantiva de información ideológicamente confiable constriñó el rango de acción de los comunistas y los obligó a depender en gran medida de las agencias estadounidenses, y a utilizar de manera instrumental la información que circulaba a través de estas y otras fuentes.

El artículo contribuye e interviene, de manera más o menos directa, en dos campos de estudio. En primer lugar, dialoga con la literatura histórica sobre la prensa, contribuyendo a nuestra comprensión de la compleja relación entre periódicos locales y agencias internacionales de noticias. La literatura ha documentado la temprana conformación de un sistema global de comunicaciones dominado por un puñado de agencias informativas. Sabemos ya bastante del funcionamiento del cartel que establecieron las agencias europeas Havas, Reuters y Wolff en la segunda mitad del siglo XIX y del posterior ingreso, en calidad de socio menor primero y de miembro con iguales derechos después, de Associated Press, así como de la eventual disolución del cartel por la acción de United Press, TASS y la ya mencionada Associated Press, durante la primera mitad de la década de 1930 (Silberstein-Loeb; Headrick y Griset; Rantanen, "Howard Interviews Stalin"). Contamos, además, con estudios relativamente detallados de lo ocurrido durante la Segunda Guerra Mundial, cuando las agencias de noticias se vieron inmersas en el juego de propaganda (Moseley; Sweeney; Tworek 196-223). Estos trabajos se han visto complementados, en los últimos años, por estudios que han analizado y evaluado la influencia de estas agencias en periódicos o países específicos, alejados de los grandes centros de poder mundial (Brennan; Caimari), y por estudios que han prestado atención a proyectos contrahegemónicos, que intentaron desafiar el orden global de la producción y distribución de la información noticiosa (Cmiel; Freije; Keller; Rivera).

Lamentablemente, aún sabemos muy poco del rol que la información proveniente del extranjero jugó en el surgimiento de la llamada "prensa moderna" en Chile, aunque dicha información empezó a adquirir prominencia tempranamente, en el último tercio del siglo XIX (Ossandón y Santa Cruz 154; Santa Cruz 65-70). No contamos con ningún estudio que examine en detalle estos asuntos, por lo menos no hasta la segunda mitad del siglo XX. Los únicos trabajos dignos de ser destacados son los de Francisco Javier Alvear y Jairo Lugo-Ocando, que se centran en El Mercurio durante los años de la Unidad Popular, y de Diego Portales, quien, cubriendo el período 1960-1973, documenta el predominio de las grandes agencias occidentales en el mercado chileno, y 
ofrece pistas sobre los intentos de algunos periódicos por proveerse material de otras agencias (103-108 y 206-210). Este artículo contribuye a llenar los vacíos existentes en la literatura chilena a través de un estudio detallado de dos periódicos, Frente Popular y El Siglo, en un momento de particular importancia en la reestructuración del mercado de noticias internacionales, iluminando las estrategias de los encargados de estos periódicos por proveerse de información noticiosa y los usos que estos hacían de dicha información.

El artículo subraya la agencialidad de los encargados de Frente Popular y El Siglo en el marco de una estructura global desigual, dominada por un puñado de centros neurálgicos localizados en Estados Unidos y Europa. Los encargados de los periódicos comunistas chilenos dependían de las agencias internacionales para informar oportunamente de los sucesos de la guerra, la mayor parte de las cuales no compartía su ideología ni su preocupación por los avatares de la Unión Soviética. Pero no por ello debe considerárseles receptores pasivos de la información que enviaban estas agencias, subordinados a una relación vertical. El establecimiento de vínculos contractuales con diversas agencias, y la utilización instrumental de la información que circulaba a través de ellas, demuestran que los encargados de los periódicos comunistas chilenos tenían un rol importante en definir qué y cómo informaban de la guerra.

En segundo lugar, este artículo es un aporte a la literatura sobre los vínculos internacionales del comunismo chileno. Silvio Pons ha sostenido recientemente, a nuestro entender de manera acertada, que los estudiosos de los partidos comunistas debiesen reconocer la centralidad de la dimensión transnacional de su objeto de estudio (xii-xiv). En lo que respecta a Chile, en particular, varios trabajos han demostrado la influencia de Komintern -e indirectamente, de la Unión Soviética- en los avatares y asuntos internos del PCCh, insoslayable entre 1927 y 1941 (Grez; Ulianova, "El Partido Comunista" y "Primeros contactos"; Urtubia). Además, tenemos una idea más o menos clara del rol clave de ciertos actores regionales que actuaron como intermediarios entre el PCCh y la Unión Soviética, sujetos como el argentino Victorio Codovilla o el peruano Eudocio Ravines (Ulianova, "Develando un mito"; Salgado y Urtubia). Para décadas posteriores, contamos con documentados estudios sobre la transferencia de dinero desde el bloque socialista (Ulianova y Fediakova) y sobre los vínculos que los comunistas chilenos tendieron con comunistas de otras latitudes (Santoni).

Este artículo se aleja de la literatura convencional sobre los vínculos transnacionales del PCCh y matiza algunos de sus énfasis. El enfoque de esta investigación, centrado en las relaciones contractuales entre empresas periodísticas y agencias de noticias, nos muestra que el comunismo chileno estaba asociado no solo -o principalmente- a la Unión Soviética y al llamado 
"movimiento comunista internacional", sino al sistema internacional en su conjunto, sistema que, en términos hemisféricos al menos, hegemonizaba Estados Unidos. Si bien el PCCh reconocía adscripción ideológica en la Unión Soviética y se esforzaba por cultivar vínculos con la misma, este dependía de las grandes agencias occidentales para informar del acontecer mundial de manera exhaustiva y oportuna, especialmente de las agencias estadounidenses. Por último, el enfoque adoptado en este artículo demuestra que el PCCh utilizó los acercamientos de la Unión Soviética a otras potencias para tejer alianzas peculiares, primero, con la embajada de Alemania y, después, con la embajada de Estados Unidos, alianzas que han sido obviadas por la literatura sobre el comunismo chileno.

Huelga advertir que este artículo no interviene de manera directa en el estudio de la postura de Chile ante los países en guerra, tema que ha despertado bastante interés, en parte porque Chile fue uno de los últimos países de la región en plegarse a la cruzada hemisférica liderada por Estados Unidos y subirse al carro de los Aliados. El artículo tiende a confirmar -y no refutar- el consenso historiográfico en torno al amplio apoyo de la opinión pública chilena a la postura de neutralidad hasta bien entrada la guerra y a la importancia de la presión estadounidense en la posterior decisión de romper relaciones con las potencias del Eje (Barros van Buren; Fermandois; Francis; Mount; Nocera). Pero, más que intervenir directamente en estos y otros debates atingentes, el artículo busca redirigir la atención de los estudiosos de las relaciones internacionales a la circulación de información noticiosa y ofrecer algunas estrategias para tematizar y analizar estos asuntos. La literatura sobre las relaciones internacionales de Chile durante los años de la guerra entrega muchas pistas sobre la importancia de estos asuntos a ojos de los contemporáneos, sean autoridades chilenas o diplomáticos extranjeros (v.gr., Fermandois 148, 162-163, 165; Mount 33, 49, 87, 122, 127; Nocera 49, 77, 111-113, 118, 126), cuestión que también documentamos, de manera somera, a lo largo de este artículo, y que, creemos, merecería ser estudiada en mayor profundidad.

Antes de comenzar el análisis, es necesario realizar algunas aclaraciones conceptuales y metodológicas. En primer lugar, es necesario aclarar que en las páginas siguientes nos centramos, exclusivamente, en la información escrita proveniente de agencias internacionales, sistematizando y analizando aquello que dice relación con textos de carácter noticioso. Por ende, dejamos de lado las fotografías e imágenes que enviaban algunas de estas agencias. Esta decisión metodológica ha redundado, además, en que no le prestemos la debida atención a los artículos firmados por corresponsales, a menos que estos estuvieran vinculados a una agencia de noticias; a los manifiestos y discursos producidos 
en el extranjero que circulaban a través de redes inter-partidarias; y a los artículos y columnas de publicaciones extranjeras que fueron reproducidos en Frente Popular y El Siglo. ${ }^{3}$ Lo mismo corre para las innumerables noticias sobre acontecimientos ocurridos en Chile que, de una u otra manera, tenían relación con el acontecer internacional. En síntesis, huelga advertir que los textos noticiosos en que aquí nos concentramos fueron solo una parte -aunque abundante- de lo que publicaron los periódicos comunistas sobre la Segunda Guerra Mundial, y que varios otros textos e imágenes contribuyeron a darle un framing o encuadre apropiado a los textos bajo análisis.

En segundo lugar, es necesario aclarar que en este artículo hablaremos de "cable" o "cables" para aludir a la información noticiosa enviada por las agencias internacionales. El término, que los mismos contemporáneos utilizaban y que servía de título para las secciones internacionales de algunos periódicos, hacía referencia a los cablegramas recibidos a través de los cables telegráficos submarinos que conectaban los puertos con lugares distantes, los cuales eran posteriormente retransmitidos a través de líneas telegráficas terrestres en forma de telegramas. Utilizaremos el término "cable" de manera laxa, para aludir a toda la información enviada por las agencias internacionales, incluyendo también aquella que era enviada por radiotransmisores o por avión. De esta manera, pretendemos simplificar un panorama tecnológico complejo, que unos años antes se había visto alterado significativamente por la radiotelegrafía. ${ }^{4}$ Huelga

Las publicaciones extranjeras cuyos artículos y columnas se reproducían con mayor frecuencia eran los periódicos comunistas Daily Worker (Nueva York), Pravda (Moscú), Izvestia (Moscú) y Krasnaya Zvezda (Moscú), aunque los textos de los tres últimos llegaban a través de agencias noticiosas, por lo que han sido contabilizados. De manera algo más ocasional, la prensa comunista chilena reproducía artículos de periódicos comunistas latinoamericanos. Ahora bien, no todos los artículos y columnas reproducidas en Frente Popular y El Siglo provenían de publicaciones comunistas. A inicios de la guerra, no era infrecuente la reproducción de artículos de revistas francesas, como $V u$ (Paris), Match (Paris) o Les Nouvelles littéraires (Paris). En los años siguientes, se reprodujeron artículos y columnas de periódicos y revistas de masas estadounidenses, como The New York Times (Nueva York), Life (Nueva York) o Fortune (Nueva York).

$4 \quad$ Las agencias occidentales Associated Press, Reuters y Havas utilizaban preferentemente el sistema de líneas telegráficas terrestres y submarinas para conectar el globo, la mayor parte de las cuales se encontraban en manos de los Aliados, aunque varias de ellas optaban por enviar noticias a Sudamérica a través de la radiotelegrafía por una cuestión de costos. La excepción a la norma, entre las grandes agencias occidentales, era United Press, que daba preferencia a la radiotelegrafía a nivel global. La agencia soviética TASS/SUPress combinaba la telegrafía y la radiotelegrafía, aunque dándole preferencia a esta última tecnología. La agencia alemana Transocean intentó desafiar la hegemonía de las grandes agencias occidentales utilizando casi exclusivamente la radiotelegrafía. Los despachos por avión eran un método de circulación de la información más lento, utilizado por agencias de menores recursos e importancia secundaria a nivel regional, como Inter-Continent News o Allied Labor News. 
además advertir que un cable no equivale necesariamente a una noticia. Si bien la mayoría de las noticias internacionales publicadas en Frente Popular y El Siglo correspondían a un solo cable, no era tampoco infrecuente que una noticia se compusiera de dos o más cables, que tenían relación con el mismo evento, como fue el caso, por ejemplo, de la noticia sobre la invasión alemana con la cual iniciamos este artículo.

\section{EL CONTROL ESTATAL DE LA DIFUSIÓN DE INFORMACIÓN NOTICIOSA SOBRE LA GUERRA}

La Segunda Guerra Mundial transformó las noticias internacionales en un asunto de relevancia no solo para la opinión pública nacional sino también para el Estado de Chile. Estas podían generar alarma en la población y afectar la seguridad pública. La primera muestra de ello tuvo lugar el 4 de septiembre de 1939, a menos de una semana de iniciada la guerra. Ese día, a las 10:35 de la noche, una estación de radio informó que el vapor Copiapó, un barco de la Armada que traía de regreso al país a numerosos chilenos que residían en Europa, se había hundido, causando revuelo en Santiago y Valparaíso. La noticia, que resultó ser falsa, alcanzó a ser retransmitida por otras emisoras radiales esa misma noche y publicada, a la mañana siguiente, por dos periódicos, produciendo además una querella pública entre United Press y Havas, que intentaron deslindar responsabilidades (El Mercurio, "El Copiapó navega" 1; La Hora, "El Copiapó navega" 1; La Opinión, "Comunicado" 5). El Gobierno tomó cartas en el asunto el 5 de septiembre, buscando reglamentar la transmisión radial de noticias de la guerra. La norma, ad hoc, prohibía a las estaciones de radio "retransmitir noticias de estaciones emisoras de países extranjeros" (pues se creía que la noticia se había originado en un boletín de Deutsches Nachrichtenbüro) y "transmitir boletines noticiosos, sobre el conflicto europeo", a menos que "se trate de informaciones proporcionadas por una agencia noticiosa o por un diario publicado en Chile, debiéndose indicar el nombre al iniciar y terminar la lectura del boletín" ( $E l$ Mercurio, "Se reglamenta" 15).

Esta fue la primera de una serie de medidas, tomadas tanto por el Ejecutivo como por el Legislativo, destinadas a controlar la difusión de noticias sobre la guerra. Antes del inicio del conflicto bélico, la normativa sobre la publicación de noticias internacionales en la prensa escrita y sobre la transmisión de noticias internacionales en las estaciones de radio era tan parca como ambigua. Prestaba escasa atención a las agencias internacionales en cuanto intermediarios relevantes, centrándose casi exclusivamente en los periódicos y las estaciones 
de radio. Durante el transcurso de la guerra, la normativa se volvió mucho más específica y detallada, regulando el actuar de los corresponsales y de las agencias internacionales, e interesándose tanto por la publicación de noticias en el interior del país como por la difusión de noticias al exterior - esto último, un tema de particular importancia para el Gobierno, que no quería ver dañada su imagen internacional ni sus relaciones con los países en guerra.

En lo que respecta a nuestro objeto de estudio, las normas pertinentes pueden clasificarse en dos: aquellas que afectaron el funcionamiento de todas las agencias internacionales y de todos los periódicos chilenos; y aquellas que afectaron el funcionamiento de las agencias internacionales vinculadas a las potencias del Eje. Entre las primeras, las normas más importantes fueron el Decreto $\mathrm{N}^{\mathrm{0}} 5.815$ de 1940, del Ministerio del Interior, que estableció la formación de un registro especial en la Dirección General de Correos y Telégrafos, en el cual debían inscribirse todas los corresponsales y agencias que enviasen al interior o exterior informaciones noticiosas, y que obligó además a cada uno de estos corresponsales y agencias a llevar un registro propio en el cual guardasen copia de las informaciones noticiosas expedidas (Ministerio del Interior, Decreto $\mathrm{N}^{\mathrm{o}} 5.815$ de 1940); y el Decreto $\mathrm{N}^{\mathrm{o}} 1.548$ de 1943, del Ministerio del Interior, que estableció que los diarios, revistas y periódicos solo podían publicar noticias de procedencia extranjera proporcionadas por agencias inscritas en el registro especial, y que al publicar dichas noticias debían identificar a la agencia que las había proporcionado, ya fuese al inicio o al final de la noticia (Ministerio del Interior, Decreto $\mathrm{N}^{\mathrm{o}} 1.548$ de 1943).

Los decretos reseñados en el párrafo anterior tenían por objeto vigilar y controlar la circulación de noticias internacionales, tornando más fácil establecer responsabilidades y sancionar legalmente a quienes resultasen culpables de difundir noticias falsas, alarmantes o tendenciosas. Esto era particularmente importante en el caótico contexto periodístico de aquellos años, puesto que la información noticiosa podía provenir de diversas fuentes (agencias internacionales, radios extranjeras, e incluso rumores, como el que parece haber dado origen a la noticia del hundimiento del vapor Copiapó) y no todos los periódicos acostumbraban a identificar la procedencia de la información que publicaban. La normativa tuvo el efecto indirecto de dificultar la reproducción de noticias de periódicos y agencias sin pagar por ello, práctica aún frecuente en la prensa de provincia, de la cual se quejaban ocasionalmente las agencias internacionales y los grandes diarios de la capital. Pero no logró eliminar la práctica del todo. Sabemos que un trabajador del periódico comunista El Popular de Antofagasta, por ejemplo, "captaba en una radio las noticias y crónicas de la guerra, trasmitidas por otras agencias cablegráficas para los diarios de la capital" (Corvalán 43). 
En lo que respecta a las normas que afectaron el funcionamiento de las agencias de las potencias del Eje, cabe destacar la Ley $\mathrm{N}^{\mathrm{o}} 7.401$, que vinculó la seguridad exterior del Estado chileno a la de los Aliados (a instancias de Estados Unidos) y estableció una serie de medidas que dificultaban la publicación de noticias que afectaban los intereses o perjudicaban "a Chile o a algún país americano o sus aliados en guerra con otro país no americano", aún antes de que el Gobierno de Chile rompiera relaciones con los países del Eje (Ministerio del Interior, Ley $\mathrm{N}^{\mathrm{o}}$ 7.401); y los Decretos $\mathrm{N}^{\mathrm{o}}$ 547, 548 y 549 de 1943, del Ministerio del Interior, que sentaron las bases para que la Dirección General de Correos y Telégrafos eliminara del registro y cancelara los permisos de las agencias vinculadas a los países del Eje, con los cuales el Gobierno de Chile había roto relaciones diplomáticas unos días antes (Ministerio del Interior, Decreto $\mathrm{N}^{\circ} 547$ de 1943, Decreto No 548 de 1943 y Decreto No 549 de 1943).

\section{LA PRENSA COMUNISTA Y LAS AGENCIAS DE NOTICIAS}

Este apartado examina los vínculos entre las empresas periodísticas del PCCh y las agencias internacionales. La Tabla 1 sistematiza información referente a la procedencia de los cables publicados en Frente Popular y El Siglo. Se han contabilizado todos los cables publicados durante una semana de enero al año, entre los años 1940 y 1945 inclusive. Hemos decidido revisar solo una semana al año porque el proceso de contabilización de cables es laborioso y porque esto nos permite hacernos un panorama general de los cambios ocurridos en el transcurso de una guerra que se prolongó por más de cinco años. Para complementar esta información, las Tablas 2 y 3 sistematizan información tanto del número de cables como del número de palabras de dichos cables, aunque solo para la semana correspondiente a enero de 1941. De nuevo, cabe aclarar que hemos optado por este método, intensivo, pero no exhaustivo, por considerarlo conveniente.

Como se puede apreciar en la Tabla 1, las noticias internacionales publicadas en la prensa comunista provenían de diversas fuentes. Por regla general, la información se basaba, principalmente, en los servicios de una agencia estadounidense, ya fuese United Press o Associated Press, de la cual provenía la mayor parte de la información publicada diariamente. En términos cuantitativos al menos, la agencia soviética TASS/SUPress y, durante los primeros dos años de la guerra, la agencia alemana Transocean, jugaron un rol que podría tildarse de complementario. ${ }^{5}$

$5 \quad$ En la Tabla 1 se aprecia un aumento gradual en el número de cables publicados entre 1940 y 1942 , y luego una disminución más o menos significativa. Esta disminución no se debe a un menor 
Las Tablas 2 y 3, que sistematizan información correspondiente a una semana de enero de 1941, nos permiten realizar ciertas aclaraciones y acotaciones. Como se deduce de la Tabla 2, la información noticiosa proveniente de TASS/SUPress y de otras agencias comunistas era algo más abundante de lo que se desprende de la Tabla 1, pues los cables de estas agencias tendían a contener más palabras que los de las agencias estadounidenses o que los de Transocean. Ahora bien, como se aprecia en la Tabla 3, las noticias de TASS/ SUPress y de otras agencias comunistas eran publicadas irregularmente. En otras palabras, la columna vertebral de la sección internacional de El Siglo estaba constituida, al menos en enero de 1941, por información proveniente de Associated Press y, en bastante menor medida, Transocean. Esta información era complementada, en algunos días de la semana, por cables provenientes de TASS/SUPress y de otras agencias ideológicamente afines, cables que eran menos frecuentes, pero más extensos.

De la Tabla 3 también puede concluirse que El Siglo publicaba en aquel entonces, a diario, entre 30 y 45 cables provenientes del exterior, para un total de palabras que iba de 4.900 a 5.500, aunque esta cifra disminuía significativamente los lunes -puesto que ese día la sección internacional se componía de una página en vez de dos- $y$, ocasionalmente, también los domingos -cuya sección internacional podía componerse de una página y media o de dos páginas.

Tabla 1. Cables publicados en la prensa comunista, 1940-1945

\begin{tabular}{|l|c|c|c|c|c|c|c|c|c|c|c|c|}
\hline \multirow{2}{*}{} & \multicolumn{2}{|c|}{1940} & \multicolumn{2}{c|}{1941} & \multicolumn{2}{c|}{1942} & \multicolumn{2}{c|}{1943} & \multicolumn{2}{|c|}{1944} & \multicolumn{2}{c|}{1945} \\
\cline { 2 - 15 } & $\#$ & $\%$ & $\#$ & $\%$ & $\#$ & $\%$ & $\#$ & $\%$ & $\#$ & $\%$ & $\#$ & $\%$ \\
\hline Associated Press & 0 & 0 & 170 & 73,59 & 207 & 82,14 & 150 & 90,91 & 0 & 0 & 0 & 0 \\
\hline United Press & 115 & 59,28 & 0 & 0 & 0 & 0 & 0 & 0 & 111 & 81,62 & 142 & 88,2 \\
\hline Transocean & 21 & 10,82 & 38 & 16,45 & 0 & 0 & 0 & 0 & 0 & 0 & 0 & 0 \\
\hline TASS/SUPress & 2 & 1,03 & 15 & 6,49 & 37 & 14,68 & 10 & 6,06 & 15 & 11,03 & 3 & 1,86 \\
\hline Inter-Continent News & 7 & 3,61 & 2 & 0,87 & 7 & 2,78 & 0 & 0 & 0 & 0 & 0 & 0 \\
\hline Especial [sic] & 49 & 25,26 & 0 & 0 & 0 & 0 & 4 & 2,42 & 2 & 1,47 & 2 & 1,24 \\
\hline Otras agencias & 0 & 0 & 6 & 2.6 & 1 & 0,4 & 1 & 0,61 & 8 & 5,88 & 14 & 8,7 \\
\hline Total & 194 & 100 & 231 & 100 & 252 & 100 & 165 & 100 & 136 & 100 & 161 & 100 \\
\hline
\end{tabular}

Fuente: Elaboración propia, basada en una revisión de Frente Popular (1940) y El Siglo (1941-1945) durante las siguientes semanas: 8-14 enero 1940; 6-12

interés de los comunistas chilenos en los asuntos internacionales, sino a la disminución en el número de páginas del periódico, provocada por los problemas de abastecimiento de papel. 
enero 1941 ; 5-11 enero $1942 ; 4-10$ enero $1943 ; 3-9$ enero $1944 ; 8-14$ enero $1945 .^{6}$

Tabla 2. Cables y palabras publicados en la prensa comunista, 1941

\begin{tabular}{|l|c|c|c|c|}
\hline \multirow{2}{*}{} & \multicolumn{2}{|c|}{ cables } & \multicolumn{2}{c|}{ palabras } \\
\cline { 2 - 5 } & $\#$ & $\%$ & $\#$ & $\%$ \\
\hline Associated Press & 170 & 73.59 & 23480 & 67.05 \\
\hline Transocean & 38 & 16.45 & 3437 & 9.81 \\
\hline TASS/SUPress & 15 & 6.49 & 5614 & 16.03 \\
\hline $\begin{array}{l}\text { Inter-Continent } \\
\text { News }\end{array}$ & 2 & 0.87 & 1065 & 3.04 \\
\hline Otras agencias & 6 & 2.6 & 1424 & 4.07 \\
\hline Total & 231 & 100 & 35020 & 100 \\
\hline
\end{tabular}

Fuente: Elaboración propia, basada en El Siglo: 6-12 enero 1941.

Tabla 3. Cables y palabras publicados en la prensa comunista, desagregado por día, 1941

\begin{tabular}{|l|c|c|c|c|c|c|c|c|c|c|c|c|c|c|}
\hline & \multicolumn{2}{|c|}{ lunes } & \multicolumn{2}{c|}{ martes } & miércoles & \multicolumn{2}{c|}{ jueves } & \multicolumn{2}{c|}{ viernes } & \multicolumn{2}{c|}{ sábado } & \multicolumn{2}{c|}{ domingo } \\
\cline { 2 - 18 } & cables & palab. & cables & palab. & cables & palab. & cables & palab. & cables & palab. & cables & palab. & cables & palab. \\
\hline $\begin{array}{l}\text { Associated } \\
\text { Press }\end{array}$ & 14 & 1891 & 16 & 2389 & 17 & 2879 & 40 & 4673 & 35 & 3754 & 35 & 3866 & 13 & 1294 \\
\hline Transocean & 2 & 227 & 9 & 573 & 13 & 1195 & 4 & 547 & 2 & 136 & 7 & 503 & 1 & 115 \\
\hline $\begin{array}{l}\text { TASS/ } \\
\text { SUPress }\end{array}$ & 0 & 0 & 3 & 1214 & 2 & 346 & 0 & 0 & 4 & 1375 & 0 & 0 & 6 & 2679 \\
\hline $\begin{array}{l}\text { Inter- } \\
\text { Continent } \\
\text { News }\end{array}$ & 0 & 0 & 0 & 0 & 0 & 0 & 0 & 0 & 0 & 0 & 2 & 1065 & 0 & 0 \\
\hline $\begin{array}{l}\text { Otras } \\
\text { agencias }\end{array}$ & 0 & 0 & 3 & 770 & 3 & 654 & 0 & 0 & 0 & 0 & 0 & 0 & 0 & 0 \\
\hline Total & 16 & 2118 & 31 & 4946 & 35 & 5074 & 44 & 5220 & 41 & 5265 & 44 & 5434 & 20 & 4088 \\
\hline
\end{tabular}

Fuente: Elaboración propia, basada en El Siglo: 6-12 enero 1941.

6 Se han contabilizado solo los cables que identifican a la agencia. He hecho una excepción con los cables identificados como "Especial", término utilizado por ambos periódicos. 


\subsection{Las agencias estadounidenses Associated Press y United Press}

Como puede apreciarse en las tablas mencionadas, los periódicos comunistas dependían significativamente de las agencias estadounidenses United Press, utilizada por Frente Popular entre 1936 y 1940 y luego por El Siglo entre 1944 y 1947; y Associated Press, utilizada intermitentemente por Frente Popular en 1940 y luego por El Siglo entre 1940 y 1943. Es posible afirmar, sin temor a equivocarnos, que las agencias estadounidenses proveyeron a los periódicos comunistas de más de la mitad de la información noticiosa internacional que estos publicaron, en cualquier momento dado, durante los años de la guerra. La proporción de los cables publicados provenientes de estas agencias se encumbraba, por lo general, sobre los dos tercios y en ciertos momentos llegó a ser de cuatro quintos. Si bien la literatura ha subrayado la problemática dependencia que se genera entre periódicos de países periféricos (de escasos recursos) y agencias internacionales (de abundantes recursos), es necesario advertir que estos vínculos les ayudaron a periódicos como Frente Popular y El Siglo a abandonar su condición de productos de nicho y competir, de igual a igual, en el mercado de periódicos chileno.

Al comenzar la guerra, en septiembre de 1939, el mercado chileno de noticias internacionales estaba dominado por United Press y Havas, siendo, en términos prácticos, un oligopolio compuesto de dos proveedores. Por regla general, los periódicos chilenos utilizaban una u otra agencia, probablemente por los altos costos que conllevaba la contratación de estos servicios. La principal excepción a la norma eran los diarios de la poderosa cadena El Mercurio, la principal empresa periodística del país, que estaban suscritos a ambas agencias. Además de Frente Popular y de los diarios de la cadena El Mercurio, la mayor parte de los periódicos de prestigio y alcance nacional utilizaban los servicios de United Press (El Diario Ilustrado, La Hora, La Nación, etc.). Da la impresión de que solo aquellos periódicos de menor prestigio y recursos, como el izquierdista La Opinión o el derechista El Imparcial -caracterizados por su lenguaje ácido y su tendencia a la controversia- utilizaban los servicios de Havas, los cuales eran de una calidad evidentemente inferior. El hecho de que los encargados de Frente Popular hubieran decidido suscribirse al servicio de United Press, de mejor calidad y presumiblemente más caro que el de Havas, es otro indicio de la importancia que los comunistas le otorgaban al acontecer internacional y de los esfuerzos que realizaron para disponer de un órgano periodístico competitivo. ${ }^{7}$

$7 \quad$ La lucha entre United Press y Havas por el mercado latinoamericano databa de la Primera Guerra Mundial, cuando la agencia estadounidense hizo su entrada en la región y comenzó a disputarle la primacía a la agencia francesa, que antes detentaba una suerte de monopolio. El dominio de 
Associated Press, que había ingresado originalmente al mercado chileno junto con United Press, pero que había decidido abandonarlo en los años siguientes, hizo su reingreso a este mercado en el transcurso de 1939, poco antes de iniciarse la Segunda Guerra Mundial. ${ }^{8}$ Frente Popular fue pionera en vincularse a Associated Press. El periódico comunista empezó a incluir cables de esta agencia durante el primer semestre de 1940, aun antes de terminar su contrato con United Press, lo que nos habla de las ansias de los editores y periodistas comunistas por proveerse de la mayor cantidad de información posible. Fue solo en el contexto de la desaparición de Frente Popular y la aparición de El Siglo, el 31 de agosto de 1940, que la prensa comunista dejó de utilizar los cables de United Press de manera definitiva, pasando a depender de Associated Press para informar del acontecer internacional. La peculiar coexistencia de información proveniente de las dos principales agencias estadounidenses en los últimos meses de vida de Frente Popular parece haberse debido a los intentos de Associated Press por reposicionarse en el mercado local. Desde la perspectiva de los comunistas, es evidente que el aumento y la diversificación de las fuentes de información era bienvenida.

La relación entre los comunistas y Associated Press se prolongó por más de tres años. Como se puede apreciar en la Tabla 1, la importancia de esta agencia dentro del periódico comunista tendió a aumentar con el tiempo. Esto se debe, en parte, a la decisión tomada por los encargados del periódico, a mediados de 1941, de no seguir utilizando los servicios de Transocean -decisión analizada más adelante- lo que redundó en una mayor presencia relativa de los cables de la agencia estadounidense. Pero el aumento también parece explicarse por la creciente confianza de los encargados del periódico comunista en la información que circulaba a través de Associated Press. Los objetivos de los comunistas chilenos y de la opinión pública estadounidense -que influía en los contenidos de Associated Press, puesto que esta era una cooperativa de periódicos- tendieron a acercarse en el transcurso de la guerra, primero con el paso de los soviéticos al campo de los Aliados, en junio de 1941, y después con el ingreso formal de Estados Unidos a la guerra, en diciembre de 1941. Estos dos eventos propiciaron una coincidencia estratégica de objetivos, en materia de política internacional, entre los comunistas chilenos y la opinión pública estadounidense. A diferencia

United Press en la región se incrementó en los años veinte y terminó de cimentarse en los treinta (Rantanen, "Mr. Howard Goes to South America").

8 Associated Press reinició sus operaciones en el país en abril de 1939. Hizo su reingreso al mercado chileno asociándose con periódicos pequeños. Los primeros en hacer uso de sus servicios parecen haber sido el periódico comunista El Popular de Antofagasta y el periódico regionalista La Verdad de Punta Arenas (The Associated Press 40). Frente Popular los siguió unos meses después. 
del resto de los periódicos chilenos, que defendían la política de neutralidad, El Siglo se sumó rápidamente al carro de los Aliados y llamó insistentemente a romper relaciones con los países del Eje, sirviéndose para esto de la información que circulaba a través de Associated Press.

El Siglo dejó de utilizar los servicios de Associated Press el 31 de diciembre de 1943, pues la agencia había firmado un contrato de exclusividad con la prestigiosa cadena El Mercurio, que regía para las provincias de Santiago y Valparaíso (El Mercurio, 1-1-1944 5; Gould) y que se terminó prolongando por varios años (Portales 103-108). Los encargados de la prensa comunista volvieron entonces a contratar los servicios de United Press. El Siglo informó del cambio de agencia en términos positivos, argumentando que "nuestro noticiario mundial será notablemente mejorado", sin aludir nunca al contrato de exclusividad que Associated Press había firmado con El Mercurio. Junto con citar cifras que destacaban los servicios de United Press a nivel global ("trabaja en 44 países en la actualidad") y local ("un personal de 66 personas"), pusieron énfasis en el compromiso de la agencia en la lucha contra el fascismo. "Al comenzar el año 1944", informó El Siglo, "la UP se prepara activamente para la Victoria y para la Paz". El periódico comunista recordó también al antiguo gerente de United Press en Chile, Reynolds Packard, subrayando que este "está ya en Italia detrás de los ejércitos, con instrucciones de abrir la oficina de la United Press tan pronto entren las tropas aliadas en Roma" (El Siglo, 1-1-1944 1). ${ }^{9}$

La utilización de los servicios cablegráficos de United Press y Associated Press les permitió a los órganos del PCCh posicionarse como medios noticiosos relevantes. La cantidad de información que circulaba a través de estas agencias era abundante: sabemos que en 1927 United Press transmitía unas 10.000 palabras diarias a los periódicos de Sudamérica (Rantanen, "Mr. Howard Goes" 19), y que en 1940 Associated Press transmitía más de 10.000 palabras diarias a los periódicos de Centroamérica y Sudamérica (The Associated Press 5). Si

Es interesante notar que, al momento de la transición, El Siglo advirtió a sus lectores que la contratación del servicio de United Press implicaba ciertos sacrificios económicos. No sabemos si ello hacía referencia a un mayor costo de los servicios de United Press, en comparación a Associated Press. De ser así, es probable que se haya debido a que el modelo de negocios de Associated Press combinaba cobros de dinero con acuerdos de reciprocidad, mientras que el de United Press se basaba exclusivamente en cobros de dinero. El vínculo contractual entre El Siglo y United Press se renovó varias veces, prolongándose hasta el 31 de diciembre de 1947. Los encargados del periódico decidieron no renovarlo al terminar aquel año, por encontrarse en una difícil situación económica y política, provocada por la persecución anticomunista desatada por el gobierno de Gabriel González Videla. Fue una decisión acertada. El periódico comunista no logró sobrevivir la arremetida gubernamental, desapareciendo en julio de 1948. 
tomamos en consideración que El Siglo en 1941 (véase la Tabla 3) publicaba de 4.900 a 5.500 palabras diarias en torno a noticias internacionales, y que estaba suscrito a más de una agencia de noticias, podemos colegir que los encargados del periódico tenían cierto margen -aunque, huelga advertir, no demasiado considerable-para seleccionar las noticias que juzgaban pertinentes y relevantes.

La información de Associated Press y United Press no solo era abundante sino también diversa. Ambas agencias contaban con decenas de sucursales alrededor del mundo y, en su afán de informar de la guerra, destinaron también corresponsales a los cuarteles generales de los Aliados en los distintos frentes de batalla. Pero cabe señalar que la información que circulaba a través de las agencias estadounidenses no se restringía a los lugares específicos desde donde se originaban los cables. Estas podían informar del resultado de una batalla naval ocurrida en el Mediterráneo triangulando información de distinta procedencia o traducir un discurso de Hitler difundido por radio desde Berlín. Además, las agencias estadounidenses tenían acuerdos con agencias de otras latitudes. Al comenzar 1940, por ejemplo, Associated Press tenía acuerdos con una treintena de agencias, entre las cuales se incluían no solo Havas de Francia y Reuters de Gran Bretaña, sino también Deutsches Nachrichtenbüro de Alemania, Stefani de Italia, Domei Tsushin Sha de Japón y TASS de la Unión Soviética (The Associated Press 5-6).

Para los comunistas chilenos, United Press y Associated Press tenían además la ventaja de contar con corresponsales en Moscú, un privilegio que, aparte de las agencias internacionales, solo podían darse un puñado de diarios occidentales de gran tiraje y uno que otro periódico de la órbita comunista (Moseley; Caldwell 172-242). Corresponsales como Henry C. Cassidy de Associated Press y Henry T. Shapiro de United Press adquirieron fama mundial en estos años, por lo que publicar sus nombres al identificar sus cables se transformó en una práctica común, que repercutía no solo en el prestigio del corresponsal y de la agencia, sino también del periódico que los publicaba. Por ejemplo, El Siglo presentó un perfil biográfico de Stalin escrito por Cassidy, "el conocido periodista norteamericano", anunciándolo como un escrito "especial para El Siglo" (El Siglo, 21-3-1943 8). No era tampoco infrecuente que los cables de las agencias estadounidenses reprodujeran extractos de editoriales de los periódicos soviéticos Pravda e Izvestia. Indudablemente, el vínculo entre las agencias estadounidenses y la Unión Soviética redundó en beneficio de periódicos comunistas como los que aquí se estudian. De hecho, puede argumentarse que la parte más sustancial de la información noticiosa sobre los avatares del Frente Oriental que publicó El Siglo provino de Associated Press y de United Press, y no de TASS/SUPress. 
Los vínculos entre los periódicos comunistas y las agencias estadounidenses eran de naturaleza eminentemente económica, pero tuvieron un curioso correlato a nivel político a partir de julio de 1941. La Operación Barbarroja transformó a los comunistas chilenos en aliados estratégicos de los funcionarios de la embajada estadounidense en Santiago, todos quienes ejercieron presión para que el gobierno de Chile rompiera relaciones diplomáticas con las potencias del Eje y colaborara con la causa de los Aliados. El vínculo comenzó a tejerse unas semanas después de la invasión alemana. A instancias de los comunistas, el 15 de julio de 1941 tuvo lugar la primera reunión entre Ricardo Fonseca, director adjunto de El Siglo, y John B. Faust, segundo secretario de la embajada. Según el informe de Faust, los comunistas buscaban granjearse el apoyo de Estados Unidos y se mostraban dispuestos a "colaborar" (play ball). Fonseca reconoció que la prensa comunista había atacado a Estados Unidos anteriormente, pero dijo que "ahora sienten que cualquier país que se opone a Hitler es amigo, y que se le bajará el tono al material anti-Americano en el futuro" (Embassy of the United States of America in Santiago, 16-7-1941).

La relación entre los dirigentes comunistas y los funcionarios de la embajada se tornó cada vez más fluida con el paso del tiempo, y parece haber llevado a la publicación en El Siglo de información noticiosa o propagandística proveniente directamente de la embajada. Sirva de muestra el siguiente extracto del informe de una conversación del 3 de marzo de 1944 entre otro funcionario estadounidense y el mismo Fonseca, ahora director principal de El Siglo:

Fonseca espera añadirle dos páginas más a El Siglo a partir del 10 de marzo, dedicándole una de estas páginas a las noticias del cable... Espera poder utilizar más de nuestro material cuando ocurra esta transformación. (Embassy of the United States of America in Santiago, 3-3-1944)

Antes de finalizar esta sección, cabe señalar que los comunistas chilenos tejieron un vínculo de naturaleza similar con los representantes diplomáticos de la Francia liberada, el que también repercutió en el material publicado en $E l$ Siglo. Desde fines de 1944, el periódico comunista empezó a publicar un número no insignificante de cables del Service Français d'Information o S.F.I., lo que explica, en parte, el aumento de los cables de la categoría "Otras agencias", en la Tabla 1, para el año correspondiente a 1945. Estos cables se originaban en París y eran facilitados por el agregado de prensa de la legación francesa en Chile, Edouard M. Legri, al parecer de manera gratuita (Federal Bureau of Investigation, 29-11-1945). El vínculo entre los comunistas chilenos y la Francia 
republicana se consolidó un tiempo después, cuando los encargados de El Siglo contrataron los servicios de Agence France Presse, la heredera de la difunta Havas.

\subsection{La agencia alemana Transocean}

Como demuestra la Tabla 1, la agencia alemana Transocean proveyó a los periódicos comunistas de un número no menor de cables noticiosos en los inicios de la guerra. Los primeros cables de la agencia alemana publicados en Frente Popular datan de fines de 1939, algunos meses después de la firma del Pacto Ribbentrop-Molotov y de comenzada la guerra. Al reemplazar a Frente Popular, El Siglo decidió continuar utilizando los servicios de la agencia alemana, lo que hizo con cierta frecuencia hasta junio de 1941, cuando la invasión alemana a la Unión Soviética hizo perentorio terminar con esta práctica.

La utilización de los servicios cablegráficos de Transocean en Frente Popular primero y El Siglo después se cimentaba en una curiosa, pero fructífera, relación entre funcionarios de la embajada alemana y dirigentes comunistas - esta relación, dicho sea de paso, ayudó también a que los comunistas consiguieran préstamos con bancos alemanes para el financiamiento de sus periódicos (Salgado 96). Por el lado alemán, parecen haber jugado roles protagónicos el encargado de Transocean, Gustav Vierling, alemán avecindado en Chile desde 1922, y el encargado de prensa de la embajada, Wilhelm Hammerschmidt, que dependía directamente del Ministerio de Propaganda de la Alemania nazi, y que había llegado a Chile desde México, de donde había sido expulsado por actividades nazistas (Federal Bureau of Investigation, 16-1-1945; Mount 32). La información que poseemos es más parca en lo que respecta a los comunistas involucrados. Volodia Teitelboim, encargado de los cables de Frente Popular y El Siglo, probablemente exorciza cierto sentimiento de culpa al sindicar como único responsable de esta relación a Eudocio Ravines, dirigente comunista de gran importancia en aquellos años, quien, tras ser expulsado, se convirtió en un vociferante crítico del comunismo (Teitelboim, Un hombre 76). Ahora bien, la relación no era la sola iniciativa de Ravines. De hecho, El Siglo siguió publicando información procedente de Transocean varios meses después de que Ravines cayera en desgracia dentro de los círculos comunistas.

La utilización de Transocean en los periódicos comunistas se explica por diversos motivos. En primer lugar, porque durante el periodo en que tuvo vigencia el Tratado de No Agresión entre Alemania y la Unión Soviética hubo coincidencia estratégica entre los objetivos de ambas potencias, que repercutió 
en la naturaleza de la información que circulaba a través de esta agencia. De hecho, las agencias alemana y soviética parecen haberse cuidado de no circular información que afectase negativamente los intereses de su contraparte. ${ }^{10}$ Transocean estaba entonces empeñada en subrayar los altos costos humanos de la guerra para los países Aliados y en denunciar los intentos de Gran Bretaña por empujar al resto de las naciones a la guerra, lo que les permitía a los comunistas chilenos abogar por una neutralidad vigilante, que era muy crítica de quienes intentaban acercar a Chile al campo de los Aliados. Además, las noticias de la agencia alemana le permitían a Frente Popular y El Siglo contrarrestar el sesgo pro-occidental y antisoviético de la información que circulaba a través de la agencia estadounidense United Press en los años iniciales de la guerra, sesgo que se dejaba sentir en varios otros de los periódicos chilenos. ${ }^{11}$ Todo esto facilitaba la tarea de los comunistas chilenos, que buscaban presentar el conflicto como una guerra inter-imperialista y que no perdían ocasión de denunciar las tendencias imperialistas de los británicos y de los estadounidenses.

En segundo lugar, la utilización de Transocean en los periódicos comunistas se explica porque esta era capaz de proveer información noticiosa relevante, de manera rápida, y a muy bajo costo. Como lo demostró una investigación del Distrito de Columbia, en Estados Unidos, contra Transocean, la agencia era fuertemente subvencionada por la Alemania nazi y no necesitaba autofinanciarse, operando, en la práctica, como un organismo de propaganda estatal (Tworek 204-207). Según un funcionario de la embajada estadounidense que conversó con el dirigente comunista Ricardo Fonseca en julio de 1941, este le habría dicho que "El Siglo había utilizado anteriormente 'algunos ítems' del servicio de Transocean porque estos les eran facilitados gratuitamente al periódico" (Embassy of the United States of America in Santiago, 16-7-1941). Además, la agencia alemana tenía el beneficio de contar con corresponsales en varios países, que transmitían información de manera rápida y regular. En los años

10 Entre los documentos del Ministerio de Relaciones de la Alemania nazi que sobrevivieron la guerra, se conservan algunos intercambios entre Joachin von Ribentropp y el embajador alemán en Moscú, en los que el primero se queja de que TASS haya circulado noticias que afectan los intereses alemanes, y le pide al embajador alemán que le transmita sus quejas y le recuerde a Viacheslav Molotov su deber de reciprocidad (véase, United States Department of State, documents 435, 438 y 440). Ulianova ha analizado las consecuencias del controversial Pacto de No Agresión en el PCCh, y cómo Frente Popular abordó el tema ("Develando un mito" 149-155).

11 Esto fue particularmente importante, por ejemplo, en el marco de la invasión soviética a Finlandia, una agresión que manchó la reputación de la Unión Soviética y que, en un comienzo, hizo dudar de su poderío militar. En ese difícil contexto, Frente Popular publicó varios cables de Transocean que se hacían eco de la interpretación soviética de los sucesos. 
iniciales de la guerra, Transocean contaba incluso con corresponsales en Moscú. De hecho, no era infrecuente que la agencia alemana circulara resúmenes de los editoriales de Pravda o Izvestia, que llegaban antes que los cables a través de los cuales TASS/SUPress reproducía dichas editoriales. Por último, cabe señalar que la información noticiosa enviada por Transocean, si bien no siempre era confiable, estaba escrita en un lenguaje esencialmente factual y versaba sobre diversos asuntos, algunos más bien triviales. ${ }^{12}$

El Siglo dejó de citar información proveniente de Transocean-al menos de forma abierta- en junio de 1941, en el marco de la invasión alemana a la Unión Soviética, y emprendió unos meses después una campaña de denuncia contra esta agencia, llamando al gobierno a tomar medidas contra ella. Las denuncias la describían como una "empresa de propaganda hitlerista", negándole su calidad de agencia informativa, y la sindicaban como una "cueva de espías" (El Siglo, 24-9-1941 8; El Siglo, 23-5-1942 1; El Siglo, 27-6-1942 1; El Siglo, 7-7-1942 3). Es probable que los comunistas hayan contado con ayuda de la embajada norteamericana -muy interesada en las actividades quintacolumnistas en Chile- en su campaña contra Transocean, pues algunas de sus denuncias eran tan informadas que daban a conocer los sueldos de los empleados de la agencia y la llegada de nuevos empleados desde Argentina y Alemania, cuestiones que difícilmente pueden haber descubierto en base a los métodos tradicionales del periodismo. A medida que los gobiernos latinoamericanos rompían relaciones con los países del Eje y tomaban medidas contra sus ciudadanos, la campaña de El Siglo se veía reforzada con información noticiosa procedente del extranjero -por lo general, vía Associated Press- sobre la clausura de las oficinas de Transocean en la región. ${ }^{13}$

12 En su estudio sobre la influencia nazi en el sur de Chile, donde se concentraban la mayor parte de los alemanes y descendientes de alemanes, Mount demuestra que El Correo de Valdivia, La Prensa de Osorno y El Llanquihue de Puerto Montt utilizaban regularmente los servicios de Transocean y United Press, pero sostiene que la mayoría de los cables de Transocean publicados en esos periódicos eran intrascendentes, no más dañiños para la causa de los Aliados que algunos de los cables de United Press.

13 Una vez que Chile rompió relaciones con los países del Eje y clausuró Transocean, en enero de 1943, El Siglo reorientó su campaña de denuncia, ahora contra quienes captaban mensajes procedentes de Alemania a través de aparatos de radio clandestinos y contra la pequeña agencia $\mathrm{PACH}$, una agencia de noticias chilena, creada unos años antes, cuyos orígenes se entrelazan con los de Transocean y la propaganda nazista en el país (Tworek 212). 


\subsection{La agencia soviética TASS/SUPress y otras agencias afines}

Las empresas periodísticas del PCCh siempre hicieron un esfuerzo por brindar información noticiosa mundial a través de fuentes afines, ya sea reproduciendo artículos de periódicos comunistas de otros países o ligándose a agencias alternativas. En esa labor cumplió un rol destacado TASS/SUPress. Los cables de esta agencia se originaban en Moscú o, durante un breve periodo, Kúibyshev (hoy llamada Samara), ciudad a la cual se trasladó la burocracia soviética tras la invasión alemana. Pero parecen haber llegado a Chile a través de sucursales de esta en Montevideo y Nueva York (Federal Bureau of Investigation, 16-1-1945).

El servicio de TASS/SUPress tenía una serie de debilidades, que ayudan a explicar porqué Frente Popular y El Siglo no reprodujeron sus cables con más frecuencia. En primer lugar, TASS/SUPress era una agencia nacional antes que internacional. A diferencia de agencias como United Press, Associated Press o incluso Transocean, que contaban con un número importante de sucursales y corresponsales en el extranjero, la agencia soviética TASS tenía como principal misión recopilar y difundir noticias al interior de la Unión Soviética, siendo el envío de noticias al exterior una función de relevancia secundaria (Kruglak, "The role"). SUPress era técnicamente un servicio aparte, operado por Komintern para difundir información noticiosa a los periódicos comunistas de otros países, pero la información que este difundía trataba exclusivamente de la Unión Soviética y se asemejaba a la de TASS, actuando en la práctica como correa de transmisión del contenido recopilado por esta última.

En segundo lugar, el servicio de TASS/SUPress no era particularmente "noticioso". TASS estaba principalmente interesada en propagar una imagen idealizada de la Unión Soviética, y sus cables incluían una buena dosis de propaganda, lo que parece haber frustrado incluso a algunos periodistas occidentales que simpatizaban con la Unión Soviética (Kruglak, The Two Faces 170-186; Rantanen, "Howard Interviews Stalin" 39).

En tercer lugar, TASS/SUPress parece haber transmitido una cantidad significativamente menor de información que las agencias estadounidenses. Mientras que United Press y Associated Press transmitían alrededor de 10.000 palabras diarias, un informe del Federal Bureau of Information (FBI) escrito a finales de 1945 señala que El Siglo recibía entonces del "Soviet Press Bureau" (que cumplía el rol que había tenido SUPress antes de la disolución de Komintern) entre 1.000 y 1.500 palabras diarias (Federal Bureau of Investigation, 29-111945). No contamos con información relativa a SUPress antes de la disolución de Komintern, pero la información sintetizada en la Tabla 3 sugiere (basándonos en este caso en la cantidad de palabras publicadas) que la cifra era similar. 
Si bien el servicio de TASS/SUPress no era todo lo informativo ni abundante que algunos hubiesen deseado, este tenía la ventaja de ofrecer una visión de primera mano de la realidad soviética y permitía además conocer la interpretación soviética de la guerra. Gracias a la agencia soviética, los comunistas chilenos pudieron leer comentarios editoriales que se publicaban en periódicos como Pravda o Izvestia y artículos de intelectuales de la talla de Ilya Ehrenburg. Los encargados de Frente Popular y El Siglo estaban orgullosos de contar con la "exclusividad" de los servicios noticiosos de TASS/SUPress en Chile, un hecho que constantemente destacaban. La sección internacional y, más ocasionalmente la portada, lo proclamaban a viva voz. Con motivo del primer aniversario de $E l$ Siglo, el Secretario General del PCCh explicitó este sentimiento de orgullo y explicó la importancia de la agencia.

Una de las características del diario que yo más celebro -y que algunos no aprecian en todo su valor-es su información cablegráfica. La agencia SUPRESS da informaciones que valen no sólo porque son exclusivas, sino porque merecen una confianza ilimitada. Yo sigo los acontecimientos mundiales a través de tales informaciones, que han demostrado ser absolutamente serias y fidedignas. (El Siglo, 31-8-1945 25)

El servicio de TASS/SUPress permitía además desmentir noticias internacionales procedentes de otras fuentes informativas, dadas a conocer en la radio o en otros periódicos chilenos. Los desmentidos de TASS/SUPress fueron particularmente abundantes durante los primeros dos años de la guerra, cuando la postura de la Unión Soviética discrepaba del resto de las potencias occidentales, a través de cuyas agencias noticiosas (Associated Press, United Press, Reuters, etc.) circulaba la mayor parte de la información noticiosa. Sirva de ilustración la llamada Guerra de Invierno entre la Unión Soviética y Finlandia, que tuvo lugar a fines de 1939 e inicios de 1940. La decisión soviética de invadir Finlandia forzó a los comunistas chilenos a asumir una postura defensiva, pues la mayor parte de las noticias publicadas en la prensa chilena eran críticas del actuar soviético y, al menos durante los primeros dos meses, subrayaban las derrotas de Ejército Rojo. La información de TASS/SUPress les permitió a los comunistas chilenos ofrecer una interpretación diferente de los acontecimientos. El 15 de julio de 1940, por ejemplo, Frente Popular anunció la publicación de noticias de TASS/SUPress con las siguientes palabras: 
Sensacional cable que nos llega de Moscú, por Supress, vía West Coast, en el que se echa por tierra la historia de las derrotas soviéticas en Finlandia. Todo era invención de las agencias aliadas: desastre de la 44 división, cerco de Salla, ayuda alemana, fineses en la frontera rusa, historias absurdas que tenían un mismo origen. (Frente Popular, 15-1-1940 1)

Durante los cuatro últimos años de la guerra, cuando el destino del mundo parecía decidirse en el Frente Oriental, los cables de TASS/SUPress tomaron una importancia aún mayor. Fue en este contexto que los encargados de la prensa comunista chilena contrataron, a través de TASS/SUPress, los servicios de José Luis Salado, un periodista español que se había exiliado en Moscú tras la derrota de los republicanos en la Guerra Civil Española y que hizo de corresponsal para El Siglo y otros periódicos de habla hispana durante la Segunda Guerra Mundial (Corvalán 43; Ríos 235-243; Teitelboim, Un hombre 75-76). A diferencia de Cassidy o Shapiro, que tendían a pulular por el peculiar mundo de corresponsales de agencias y periódicos "burgueses", Salado era parte del grupo de corresponsales extranjeros que militaban o simpatizaban con el comunismo, como Janet Weaver de Daily Worker u Homer Smith de Associated Negro Press (Caldwell 178). Junto con Jesús Hernández, ex ministro comunista del gobierno de Juan Negrín durante la Segunda República Española, Salado parece haber sido el único corresponsal de habla hispana radicado en la Unión Soviética por aquel entonces. Si bien los cables de Salado en El Siglo no eran frecuentes, estos tendían a ser largos y fueron publicados durante un período relativamente extenso de tiempo, que va de al menos diciembre de 1941 a marzo de 1943, generalmente recordándosele a los lectores de su exclusividad.

Estirando ligeramente la definición, Salado podría considerarse un corresponsal de guerra, una categoría de corresponsales que adquirió fama internacional precisamente en estos años. El Siglo publicó varios reportajes que contribuyeron a realzar la épica de este tipo de corresponsales, tanto de las agencias estadounidenses como de TASS/SUPress. De esta última, por ejemplo, El Siglo publicó reportajes desde el frente de batalla de S. Loskutov y A. Poliakov. Del primero se publicaron una docena de artículos, entre diciembre de 1941 y enero de 1942, relatando sus aventuras junto a los soldados soviéticos en el Frente Oriental. Del segundo se publicaron seis artículos, en diciembre de 1942, que fueron presentados como si fuesen "escritos por el corresponsal de guerra de El Siglo, muerto en el frente soviético" (El Siglo, 4-12-1942 1). Ahora bien, huelga advertir que el periódico chileno utilizaba el distintivo de "corresponsal" y "corresponsal de guerra" de manera bastante laxa, especialmente cuando se 
trataba de periodistas que trabajaban para TASS/SUPress. El mismo Loskutov fue descrito, algo mañosamente, como "redactor de Estrella Roja, de Moscú, y corresponsal de El Siglo" (El Siglo, 2-12-1941 3).

Aparte de TASS/Supress, los periódicos comunistas chilenos estuvieron suscritos a varias otras agencias ideológicamente afines durante los años de la guerra. Algunas de ellas, como Inter-Continent News o Allied Labor News, merecen algunas líneas, pues fueron utilizadas con cierta regularidad y nos dan pistas sobre la importancia de las redes hemisféricas del comunismo. Inter-Continent News (a veces llamada, incorrectamente, Inter-Continental News) tenía su origen en un acuerdo entre el Partido Comunista de Estados (CPUSA) y TASS/Supress, que le permitía a este partido proveerse de noticias provenientes de la Unión Soviética sin costo, a cambio de recopilar y enviar noticias sobre sucesos ocurridos en Estados Unidos. Inter-Continent News operaba autónomamente, y tenía corresponsales propios alrededor del mundo y acuerdos con varias otras agencias. Los cables publicados en Frente Popular y El Siglo provenían generalmente de ciudades estadounidenses (Washington, Nueva York, Seattle, etc.), pero un número no menor se originaba en el Viejo Mundo (Londres, París y Chongqing, principalmente).

Allied Labor News era una agencia pequeña, formada en 1941, también a instancias del CPUSA, con el objeto de recopilar información noticiosa de naturaleza sindical en Estados Unidos. Con el paso del tiempo la agencia se amplió a otros temas y empezó a distribuir información a otros países, llegando a tener unos 150 periódicos suscritos, entre ellos El Siglo. Los cables de esta agencia publicados en el órgano de los comunistas chilenos se originaban principalmente en Nueva York, Washington y Londres, aunque parecen haber sido enviados a Santiago por avión, desde la oficina central de la agencia en Nueva York (Federal Bureau of Investigation, 29-11-1945).

\section{EL TRABAJO DE LOS EDITORES Y ENCARGADOS DE CABLES COMUNISTAS}

Este apartado explica y da algunos ejemplos ilustrativos del trabajo periodístico y editorial involucrado en la publicación de noticias internacionales en Frente Popular y El Siglo. Tenemos una idea más o menos fiel de ello gracias a las memorias del entonces joven escritor comunista Volodia Teitelboim, quien se desempeñó como encargado de cables de Frente Popular y El Siglo. Su trabajo consistía, primero, en seleccionar los cables que serían publicados ("debía seleccionar a toda máquina los cables", "todos los días yo seguía seleccionando cables", "los cablegramas se acumulan en varias mesas", etc.) y, después, en 
darles un título adecuado, función esta última que cumplía a veces de manera grandilocuente ("pones en los títulos la expresión 'conflicto total' y subrayas que nada se excluye como objetivos militares"). Las memorias de Teitelboim no dan indicios de que su trabajo implicase editar, recortar o alterar el contenido de los cables. Da la impresión de que, debido a la legislación, a la naturaleza factual de la mayoría de los cables (especialmente aquellos de United Press, Associated Press y Transocean) y al lenguaje ideológicamente pertinente del resto (como los de TASS/SUPress o Inter-Continent News), los periodistas comunistas rara vez los recortaban o alteraban antes de publicarlos (Teitelboim, Un muchacho 356357; Teitelboim, Un hombre, 79-81, 166-170, 322-325).

El trabajo propiamente editorial de los encargados de las noticias internacionales de Frente Popular y El Siglo comprendía, entonces, las siguientes tareas: (a) la selección de los cables a publicarse y, ocasionalmente, el agrupamiento de dos o más cables para formar una sola noticia; (b) la redacción de títulos pertinentes y de otros elementos anexos, que transformaban los cables en artículos noticiosos; y (c) el ordenamiento de estos artículos dentro del periódico. Se procederá a analizar cada una de estas tareas con cierto nivel de detalle, intentando hacer visible el trabajo editorial de los periodistas y encargados de Frente Popular y El Siglo.

\subsection{La selección de los cables}

De todas las tareas mencionadas arriba, tal vez la más difícil de apreciar y la más importante de todas era la de selección. Lamentablemente, solo sabemos fehacientemente de la recepción de los cables que fueron efectivamente publicados. Sin embargo, basándose en los cables publicados por los periódicos comunistas y en aquellos publicados por otros periódicos del país, es posible decir algunas palabras al respecto. En líneas generales, los periódicos comunistas pusieron un énfasis prioritario en los sucesos que tenían lugar en Europa y, a partir de la Operación Barbarroja, en el Frente Oriental. Le otorgaban muchísima importancia a informar del devenir de la Unión Soviética, aunque rara vez publicaban cables que transmitían información de carácter desmoralizante, a menos que su objeto fuese el de subrayar la barbarie nazi. Esta interpretación "optimista" o "triunfalista" de los sucesos se veía reforzada por la tendencia de los editores del periódico a resaltar los triunfos y minimizar las derrotas soviéticas. Por regla general, no se publicaban cables que pudiesen ser considerados "dañinos" para la imagen de la Unión Soviética, aunque sabemos que estos circularon profusamente a través de las agencias estadounidenses antes de junio de 1941. 
En los periódicos analizados se aprecia también un pronunciado interés por los sucesos ocurridos en el continente americano y que tenían relación con la guerra. Los comunistas informaban frecuentemente de lo que sucedía en Estados Unidos y en el gobierno de Franklin D. Roosevelt en particular, ya fuese para denunciar sus tendencias belicistas e imperialistas (antes de junio de 1941) o para alabar su iniciativa militar y su compromiso hemisférico (después de junio de 1941), sirviéndose para ello del gran caudal de cables que les proveían las agencias estadounidenses. Se informaba también con bastante regularidad de lo que sucedía en América Latina, ya fuese para denunciar el seguidismo de algunos gobiernos de la región (antes de junio de 1941) o para alabar su decisión de sumarse a los Aliados (después de junio de 1941). Entre junio de 1941, cuando Alemania invadió la Unión Soviética, y enero de 1943, cuando Chile rompió relaciones con los países del Eje, El Siglo desarrolló una insistente campaña contra la política de neutralidad del gobierno, echando mano de los cables de Associated Press originados en Washington que estimulaban la idea de sumarse al campo de los Aliados y de aquellos originados en otros países de la región que informaban de la decisión de romper relaciones con las potencias del Eje tomadas por los gobiernos de turno. Además, gobiernos como los de Castillo, Ramírez y Farrell en Argentina o como el de Villarroel en Bolivia, eran frecuentemente denunciados por su actitud vacilante con las potencias del Eje, utilizando para ello información proveniente de las agencias estadounidenses. El detallado panorama noticioso del continente americano que se publicó en El Siglo durante los años de la guerra era facilitado por la nutrida red de corresponsales y sucursales de Associated Press y United Press en la región.

\subsection{La titulación de los cables}

Los títulos y textos anexos (el epígrafe, la bajada, los subtítulos de los apartados, etc.) que por regla general acompañan estos cables y que, no está demás decir, los transforman en artículos noticiosos propiamente tales, también reflejan la línea editorial de los periódicos. Si bien los periodistas de Frente Popular y El Siglo no parecen haber alterado el contenido de los cables, los títulos y textos anexos que elegían para enmarcar dichos cables eran decidores. Fue en base a estos recursos que lograron darles a los cables internacionales un framing o encuadre apropiado.

Sirvan de ejemplo algunas noticias publicadas en El Siglo durante el primer semestre de 1941, es decir, antes del giro en la línea estratégica de los comunistas. La primera noticia, del 7 de enero, es sobre la Francia de Vichy, 
y está basada en un cable transmitido por la agencia alemana Transocean. La noticia informa del hallazgo de una "imprenta secreta comunista" en Tolón, responsabilizando de ello al "francés naturalizado Lupi Otello", quien, después de ser interrogado, confesó haber impreso "35.000 volantes" y dio algunos detalles sobre la distribución de la propaganda comunista en esa ciudad. El cable es breve y factual, y la noticia podría interpretarse de diversas maneras, dependiendo de la visión que tiene el lector del comunismo y su activismo clandestino. Pero el título que escogieron los editores de El Siglo para informar del suceso no daba lugar a ambigüedades y posicionaba decididamente al lector en el campo de la resistencia: "Heroica lucha de comunistas en Francia". Este título se acompañaba de una bajada que, además de aclarar el contenido de la noticia, celebraba la perseverancia de los comunistas franceses en la clandestinidad: "Otra imprenta ilegal descubrió la policía". Este ejemplo nos demuestra el poder de títulos y textos anexos en la apropiación y resignificación de la información noticiosa que se transmitía a través de los cables internacionales, incluso de aquellos que provenían de agencias ideológicamente antagónicas y que podían prestarse para interpretaciones que contradecían la postura del periódico (El Siglo, 7-1-1941 $3) .{ }^{14}$

El segundo ejemplo es una noticia del 12 de enero, compuesta de cuatro cables de Associated Press, originados en distintas ciudades europeas. Los primeros dos cables informaban de los bombardeos de aviones alemanes sobre Londres y Portsmouth, en Inglaterra, y los dos cables siguientes de los bombardeos de aviones británicos sobre Turín, en Italia, y sobre Brest y El Havre, en Francia. Los periodistas de El Siglo decidieron agrupar estos cuatro cables, tangencialmente relacionados entre sí, para formar una sola noticia, que titularon "La guerra de destrucción". Ofrecían así una visión eminentemente negativa de la guerra, que subraya la destrucción que esta producía y que no diferenciaba mayormente a los bandos en conflictos (El Siglo, 12-1-1941).

Esta utilización instrumental de la información noticiosa proveniente del extranjero, con el objeto de presentar la guerra como un conflicto inter-

Es difícil tener una idea exacta del contenido original del cable de Transocean. Las noticias sobre el acontecimiento encontradas en diarios franceses son breves y hablan de este en términos similares, aunque describen a Lupi Otello como un "italiano naturalizado francés" y hablan de "3.500" volantes. Nos inclinamos a creer que las imprecisiones y errores provienen de problemas de transmisión de la información y no son una alteración intencionada de El Siglo. De hecho, es interesante notar que la expresión "francés naturalizado" que se utiliza en El Siglo para describir a Otello, y que en un contexto xenófobo como el de la Francia de Vichy podría leerse como una denuncia de la naturaleza internacional del comunismo, no parece haberles generado problemas a los comunistas chilenos. 
imperialista, innecesario y destructivo, es aún más patente en una noticia del 15 de junio de 1941, es decir, poco tiempo antes de la invasión alemana a Rusia y del drástico giro de la política exterior comunista. La noticia en cuestión se titula "Más de cien mil toneladas destruidas cuesta un día de guerra imperialista", y se compone de dos cables de Associated Press y uno de Transocean, reproducidos en distintos apartados, identificados con títulos de menor tamaño. Uno de los cables de Associated Press proviene de Londres e informa que submarinos británicos que operan en el Mediterráneo han hundido siete barcos enemigos. El cable de Transocean proviene de Berlín e informa que bombardeos alemanes destruyeron varios barcos ingleses en el Canal de San Jorge. Los encargados de El Siglo decidieron titular el cable de Associated Press con la frase "Barbarie británica" y el de Transocean con la frase "Barbarie nazi". De esta manera, los periodistas comunistas no solo plantearon una equivalencia moral entre los contendientes, sino también subvirtieron el propósito original de los cables de Associated Press y Transocean, los cuales, al informar de acciones militares exitosas, buscaban levantar la moral de los lectores que se identificaban, respectivamente, con los Aliados y con el Eje, en el marco de la guerra de propaganda de la que se hicieron parte las agencias de noticias (El Siglo, 15-6-1941 6).

\subsection{El ordenamiento de las noticias}

La tercera tarea de naturaleza editorial realizada por los encargados de Frente Popular y El Siglo consistía en ordenar y diagramar estas noticias dentro del periódico. Noticias provenientes de agencias internacionales pueden encontrarse en cinco lugares o secciones de ambos periódicos: la portada, la sección internacional propiamente tal, la página editorial, la sección cultural y la sección deportiva. Como es de suponer, la gran mayoría de noticias provenientes de agencias internacionales se concentran en la sección internacional, aunque la portada y la página editorial contienen una minoría no despreciable, por lo que nos abocaremos a estudiar estas tres secciones; la inclusión de noticias internacionales en la sección cultural y en la deportiva es tan infrecuente que puede considerarse estadísticamente irrelevante.

La sección internacional se componía, generalmente, de tres páginas en Frente Popular y de dos páginas en El Siglo, aunque ello estuvo condicionado por la mayor o menor accesibilidad del papel de imprenta, un bien que se tornó escaso en el contexto de la guerra. Por regla general, la sección internacional se identificaba con un nombre de cabecera: "Cables" en Frente Popular, "El mensaje cotidiano del mundo" en El Siglo, al menos durante los primeros años. 
Era también frecuente la inclusión en la cabecera de la sección de un lema o slogan que elogiaba las fuentes noticiosas del periódico, como "Servicio cablegráfico Associated Press y exclusivos Intercontinental News, Supress y corresponsales especiales" o "Noticias de la Associated Press e informaciones exclusivas de Moscú, transmitidas por Supress". Estos lemas, si bien factualmente correctos, tendían a sobrevalorar la importancia de las agencias ideológicamente afines. ${ }^{15}$

Como explicamos arriba, la sección internacional concentraba la mayoría de las noticias provenientes de las agencias internacionales. Las noticias más importantes -importancia que se deduce del tamaño de los titulares y la cantidad de párrafos que componían dichas noticias- tendían a situarse en la parte de arriba de la página o páginas que componían la sección, y eran ocasionalmente acompañadas de fotografías. La mayor parte de las noticias destacadas en la parte superior de las páginas internacionales decían relación con la guerra en Europa. Si bien la sección internacional entremezclaba cables de distintas agencias sin mayor orden, ocasionalmente se les reservaba una página o una parte de una página a los cables provenientes de agencias ideológicamente afines, con el objeto de destacarlos. Cables especialmente breves, y de menor relevancia, eran ocasionalmente agrupados en un apartado que llevaba el nombre de "Noticias breves del cable" o simplemente "Noticias".

Las portadas de Frente Popular y El Siglo se componían de un puñado de noticias. La mayoría de las noticias publicadas en la portada de estos periódicos eran de carácter nacional, y tenían relación con el acontecer político, aunque, obviamente, este se entrelazaba ocasionalmente con los sucesos internacionales. Pese al sesgo "nacional" de las portadas de ambos periódicos, es evidente -en una mirada de más larga duración- que las noticias internacionales se posicionaron en la portada de manera mucho más frecuente durante los años de la guerra. La recurrencia de las noticias internacionales en la portada del periódico aumentó drásticamente a partir de la Operación Barbarroja, en junio de 1941, especialmente una vez que la Unión Soviética logró recuperarse militarmente y reconquistar territorio. Sirvan de ejemplo las portadas de El Siglo de la semana que va del lunes 4 al domingo 10 de enero de 1943. Las siete portadas en cuestión incluyen un total de 52 noticias, de las cuales 21 se basan en información de agencias internacionales.

15 Muy rara vez se destacó la inclusión de los servicios de la agencia alemana Transocean, aunque, por un breve período, el logo de El Siglo en la portada hizo alusión a la gran diversidad de las fuentes de información de las que se nutría el periódico, mencionándola: “Agencias cablegráficas: Associated Press y Transocean y Servicios Exclusivos de Supress e Intercontinent News. Corresponsales Especiales en el Extranjero y en el Interior" (véase, por ejemplo, El Siglo, 19-11$19405)$. 
Por último, cabe la pena advertir que algunas noticias internacionales eran ocasionalmente insertadas en lo que podríamos llamar la página o sección editorial. Una parte de la explicación de esta curiosa organización de la información parece residir en un tema meramente espacial. Da la impresión de que cuando cables relevantes llegados a última hora no tenían ya cabida en la sección internacional, eran destinados a la sección editorial. La otra parte de la explicación, más relevante para nuestros fines, se debe a la tendencia de la prensa comunista a realzar los cables procedentes de agencias ideológicamente afines, como TASS/Supress e Inter-Continent News, lo que llevaba a los encargados de estos periódicos a incluir algunos de estos cables en la sección editorial, separándolos del resto. Esta decisión editorial no debe extrañarnos en demasía, pues una parte significativa de la información cablegráfica que circulaba a través de estas agencias entremezclaba lo propiamente noticioso con el comentario político.

\section{CONCLUSIÓN}

Este artículo ha documentado la recepción y publicación de noticias internacionales en la prensa comunista chilena durante un período particularmente turbulento de la historia mundial. Ha demostrado que las empresas periodísticas del PCCh recurrieron a distintas fuentes de información, incluyendo, de manera prominente, las agencias estadounidenses United Press y Associated Press, la agencia soviética TASS/SUPress y, durante los dos primeros años de la guerra, la agencia alemana Transocean. Los vínculos entre los comunistas chilenos y estas agencias eran de naturaleza eminentemente contractual, pero, en algunos casos, tuvieron interesantes correlatos a nivel político y diplomático. Los encargados de la prensa comunista se sirvieron de los acercamientos de la Unión Soviética a Alemania, primero, y Estados Unidos, después, para tejer vínculos con los representantes diplomáticos de estas potencias, que parecen haber facilitado la llegada (y, en ciertas ocasiones, aumentado la cantidad) de información noticiosa.

Si los encargados de Frente Popular y El Siglo no se resignaron a depender exclusivamente de TASS/SUPress y agencias afines, y se arriesgaron a tejer vínculos y utilizar cables procedentes de otras fuentes, menos confiables en términos ideológicos, esto se debió a que estaban obligados a responder a las demandas informativas de la opinión pública que aspiraban a influenciar; que las agencias afines no eran capaces de proporcionarles información lo suficientemente abundante y diversa; que existió, al menos durante un tiempo, cierta coincidencia entre sus objetivos y los de las agencias estadounidenses 
y alemana; y que estaban bastante confiados en que, disponiendo de una cantidad más vasta y diversa de información, podían informar de la actualidad internacional en términos satisfactorios, ya fuese seleccionando cables que eran políticamente pertinentes o resignificando aquellos que eran inocuos o, incluso, potencialmente peligrosos.

Los encargados de estos pequeños periódicos experimentaron con especial intensidad el dilema de las fuentes de información (su accesibilidad, sus costos, su contenido, su confiabilidad, etc.), pues tuvieron que defender posturas minoritarias e interpretaciones inverosímiles, en un clima mediático por lo general hostil, que, en lo que al acontecer internacional respecta, estaba condicionado por la información proveniente de las grandes agencias occidentales y operaba bajo el marco de un sistema internacional hegemonizado por Estados Unidos. Pero los encargados de estos periódicos estuvieron lejos de ser víctimas de las condiciones estructurales adversas en las que tuvieron que actuar o receptores pasivos de la información que circulaba a través de estas agencias. Por el contrario, aprovecharon las oportunidades que les ofrecía el sistema internacional para forjar alianzas estratégicas, que redundaron en la información noticiosa a su disposición, y demostraron ingenio y sagacidad a la hora de utilizar esta información, dando a conocer el acontecer internacional de una manera que reforzaba -y no contradecía- su visión de mundo.

El PCCh puede haber sido un actor secundario y poco influyente en el sistema de partidos chileno, incapaz de forzarle la mano al Gobierno por sí solo, pero me atrevería a sostener que, a través de sus órganos de prensa y de las alianzas que tejió con agencias y diplomáticos estadounidenses, contribuyó a la gestación de un ambiente mediático que hizo plausible imaginar y luego concretar la ruptura de relaciones diplomáticas con los países del Eje. Una vez que Alemania invadió la Unión Soviética, los comunistas se transformaron en uno de los principales promotores de la campaña que llamaba a que el país se pusiera del lado de los Aliados, campaña que agarró vuelo en el transcurso de 1942 y facilitó que el Gobierno, con el beneplácito del Congreso, rompiera relaciones con Alemania, Italia y Japón a inicios de 1943. 


\section{REFERENCIAS BIBLIOGRÁFICAS}

Alvear, Francisco Javier y Jairo Lugo-Ocando. "When Geopolitics Becomes Moral Panic. El Mercurio and the Use of International News as Propaganda against Salvador Allende's Chile (1970-1973)". Media History, vol. 24, nos. 3-4, 2018, pp. 528-546. https://doi.org/10.1080/13688804.2016.1211929

Barros van Buren, Mario. La diplomacia chilena en la Segunda Guerra Mundial. Empresa Editora Arquen, 1998.

Brennan, James R. "The Cold War Battle Over Global News in East Africa: Decolonization, the Free Flow of Information, and the Media Business, 1960-1980". Journal of Global History, vol. 10, no. 2, July 2015, pp. 333-356. https://doi.org/10.1017/S1740022815000091

Caimari, Lila. "News from Around the World: The Newspapers of Buenos Aires in the Age of the Submarine Cable, 1866-1900". Hispanic American Historical Review, vol. 96, no. 4, November 2016, pp. 607-640. https://doi.org/10.1215/00182168-3677615

Caldwell, Jay E. "Erskine Caldwell, Margaret Bourke-White, and the Popular Front (Moscow 1941)". Tesis doctoral, University of Arizona, 2014.

Cmiel, Kenneth. "Human Rights, Freedom of Information, and the Origins of Third-World Solidarity". Truth Claims: Representation and Human Rights, editores Mark Philip Bradley y Patrice Petro. Rutgers University Press, 2002, pp. 107-130.

Corvalán, Luis. De lo vivido y lo peleado. Memorias. LOM Ediciones, 1997.

Fermandois, Joaquín. Mundo y fin de mundo. Chile en la política mundial, 19002004. Ediciones Universidad Católica de Chile, 2005, pp. 145-171.

Francis, Michael J. The Limits of Hegemony: United States Relations with Argentina and Chile during World War II. University of Notre Dame Press, 1977.

Freije, Vanessa. "The 'Emancipation of Media': Latin American Advocacy for a New International Information Order in the 1970s". Journal of Global History, vol. 14, no. 2, July 2019, pp. 301-320.

https://doi.org/10.1017/S1740022819000081

Grez, Sergio. "Las relaciones entre el Komintern y el Partido Comunista de Chile (1922-1941)". Revista de Historia Social y de las Mentalidades, vol. 24, no. 1, 2020, pp. 207-248. https://doi.org/10.35588/rhsm.v24i1.4303

Headrick, Daniel R. y Pascal Griset. "Submarine Telegraph Cables: Business and Politics, 1838-1939". Business History Review, vol. 75, no. 3, Autumn 2001, pp. 543-578. https://doi.org/10.2307/3116386. 
Keller, Renata. "The Revolution Will Be Teletyped: Cuba's Prensa Latina News Agency and the Cold War Contest Over Information". Journal of Cold War Studies, vol. 21, no. 3, Summer 2019, pp. 88-113. https://doi.org/10.1162/jcws a 00895 .

Kruglak, Theodore E. The Two Faces of Tass. University of Minnesota Press, 1962.

-----. "The Role and Evolution of Press Agencies in the Socialist Countries". Gazette, vol. 21, no. 1, February 1975, pp. 1-18.

Loyola, Manuel. "Diario El Siglo: Autoimagen y rol entre 1940-1973", Латиноамериканский Исторический Альманах, по. 22, 2019, pp. 235-255. http://doi.org/10.32608/2305-8773-2019-22-1-235-255.

Millas, Orlando. Memorias. En tiempos del Frente Popular. Ediciones Chile América CESOC, 1993.

Mount, Graeme S. Chile and the Nazis: From Hitler to Pinochet. Black Rose Books, 2002.

Moseley, Ray. Reporting War: How Foreign Correspondents Risked Capture Torture and Death to Cover World War II. Yale University Press, 2017.

Nocera, Raffele. Chile y la guerra. 1933-1943. LOM Ediciones y Ediciones de la Dibam, 2006.

Ossandón, Carlos y Eduardo Santa Cruz. El estallido de las formas: Chile en los albores de la cultura de masas. LOM Ediciones, 2005.

Partido Comunista de Chile. Ricardo Fonseca. Combatiente ejemplar. Ediciones 21 de julio, 1952.

Pons, Silvio. The Global Revolution. A History of International Communism, 1917-1991. Oxford University Press, 2014.

Portales, Diego. Poder económico y libertad de expresión. Nueva imagen, 1981. Rantanen, Terhi. "Howard Interviews Stalin: How the AP, UP, and TASS Smashed the International News Cartel". Roy W. Howard Monographs in Journalism and Mass Communication Research, no. 3, 1994, pp. 1-52.

-----. "Mr. Howard Goes to South America: The United Press Association and Foreign Expansion". Roy W. Howard Monographs in Journalism and Mass Communication Research, no. 2, 1992, pp. 1-32.

Ríos, Juan A. "El singular caso de José Luis Salado". Laberintos. Revista de estudios sobre los exilios culturales españoles, vol. 14, 2014, pp. 235243.

Rivera, Sebastián. "Latin American news agency should be formed...: Las agencias de noticias internacionales en el México posrevolucionario, 1920-1934". Secuencia, no. 92, mayo-agosto 2015, pp. 167-192. https://doi.org/10.18234/secuencia.v0i92.1338 
Rivera, Carla y Alfonso Salgado. "Más que una improvisación. Cartografía de las estrategias periodísticas del Partido Comunista de Chile, 1930-1970”. Historia 396, vol. 10, no. 2, julio-diciembre 2020, pp. 263-296. http:// www.historia396.cl/index.php/historia396/article/view/452

Rojas, Jorge. "La prensa obrera chilena: El caso de La Federación Obrera y Justicia, 1921-1927." 1912-2012: El siglo de los comunistas chilenos, editado por Olga Ulianova, Manuel Loyola y Rolando Álvarez, Universidad de Santiago de Chile, 2012, pp. 23-80.

Salgado, Alfonso. "El Partido Comunista de Chile y la empresa periodística de El Siglo: Apuntes sobre sus orígenes y desarrollo". Revista de Historia y Geografía, no. 40, junio 2019, pp. 83-110. https://doi.org/10.29344/07194145.40.1922

Salgado, Alfonso y Ximena Urtubia. "Del sindicalismo libre al sindicalismo legal: La Comintern y el viraje táctico del comunismo en Chile". Izquierdas, no. 39, abril 2018, pp. 57-85. http://dx.doi.org/10.4067/S0718-50492018000200057

Santa Cruz, Eduardo. "Conformación de espacios públicos, masificación y surgimiento de la prensa moderna en Chile: Siglo XX". Centro de Investigaciones Sociales de la Universidad Arcis, Documento de Trabajo no. $28,1998$.

Santoni, Alessandro. El comunismo italiano y la vía chilena. Los orígenes de un mito político. Ril Editores, 2011.

Silberstein-Loeb, Jonathan. The International Distribution of News: The Associated Press, Press Association, and Reuters, 1848-1947. Cambridge University Press, 2014.

Sweeney, Michael S. Secrets of Victory: The Office of Censorship and the American Press and Radio in World War II. University of North Carolina Press, 2001.

Teitelboim, Volodia. Un hombre de edad media. Editorial Sudamericana, 1999. -----. Un muchacho del siglo veinte. Editorial Sudamericana, 1997.

Tworek, Heidi J. S. News from Germany: The Competition to Control World Communications, 1900-1945. Harvard University Press, 2019.

Ulianova, Olga. "Develando un mito: Emisarios de la Internacional Comunista en Chile". Historia, vol. 41, no. 1, enero-junio 2008, pp. 125-144. http:// dx.doi.org/10.4067/S0717-71942008000100005

-----. "El Partido Comunista chileno durante la dictadura de Carlos Ibáñez (19271931): primera clandestinidad y 'bolchevización' estaliniana”. Chile en los archivos soviéticos 1922-1991. Tomo 1: Komintern y Chile 1922- 
1931, editado por Olga Ulianova y Alfredo Riquelme, Ediciones de la DIBAM, 2005, pp. 215-248.

-----. "Primeros contactos entre el Partido Comunista de Chile y el Komintern: 1922-1927". Chile en los archivos soviéticos 1922-1991. Tomo 1: Komintern y Chile 1922-1931, editado por Olga Ulianova y Alfredo Riquelme, Ediciones de la DIBAM, 2005, pp. 93-109.

Ulianova, Olga y Eugenia Fediakova. "Algunos aspectos de la ayuda financiera del Partido Comunista de la URSS al comunismo chileno durante la Guerra Fría". Estudios Públicos, no. 72, 1998, pp. 113-48.

United States Department of State. Documents on German Foreign Policy, Serie D, vol. 8: The War Years: September 4, 1939 - March 18, 1940. U.S. Government Printing Office, 1954.

Urtubia, Ximena. Hegemonía y cultura política en el Partido Comunista de Chile. La transformación del militante tradicional (1924-1933). Ariadna Ediciones, 2017.

\section{Fuentes hemerográficas}

"El Copiapó navega sin novedad frente a las costas portuguesas". El Mercurio, 5-9-1939, p. 1.

"Se reglamenta transmisión por radio de noticias de la guerra". El Mercurio, 6-9-1939, p. 15.

"Servicios cablegráficos de El Mercurio". El Mercurio, 1-1-1944, p. 5.

"Heroica lucha de comunistas en Francia". El Siglo, 7-1-1941, p. 3.

"La guerra de destrucción". El Siglo, 12-1-1941, p. 6.

"Más de cien mil toneladas destruidas cuesta un día de guerra imperialista". El Siglo, 15-6-1941, p. 6.

"Hitler inició ataque a la patria socialista". El Siglo, 22-6-1941, p. 5.

"En 6 mil ejemplares aumentó la tirada de El Siglo en quince días". El Siglo, 10-7-1941, p. 1.

"A mi juicio, la fundación de El Siglo ha sido un acontecimiento de importancia política nacional”. El Siglo, 31-8-1941, p. 25.

“La 'Transocean' burla las leyes chilenas”. El Siglo, 24-9-1941, p. 8.

"Un corresponsal de 'El Siglo' estuvo en la retaguardia alemana, en Rusia". El Siglo, 2-12-1941, p. 3.

"Radio Hucke foco de propaganda fascista". El Siglo, 23-5-1942, p. 1.

"Hermann Fickert, jefe autónomo de la agencia fascista T.O." El Siglo, 27-61942, p. 1. 
“La 'Transocean’ refugio de espías nazis en Chile”. El Siglo, 7-7-1942, p. 3.

"Aviso sin título". El Siglo, 4-12-1942, p. 1.

"Stalin visto por Cassidy". El Siglo, 21-3-1943, p. 8.

"La U.P. desde hoy en E1 Siglo". El Siglo, 1-1-1944, p. 1.

"Lea en la página 11". Frente Popular, 15-1-1940, p. 1.

"El Copiapó navega sin novedad en el Atlántico". La Hora, 5-9-1939, p. 1.

"Comunicado de la agencia Havas". La Opinión, 6-9-1939, p. 5.

\section{Fuentes archivísticas}

Embassy of the United States of America in Santiago, despatch no. 1.668, enclosure no. 2, 16-7-1941. National Archives and Administration, Record Group 59, Decimal File 1940-44, Box 4410.

-----, despatch no. 9.014, enclosure no. 1, 3-3-1944. National Archives and Administration, Record Group 59, Decimal File 1940-44, Box 3079.

Federal Bureau of Investigation, "El Siglo", 29-11-1945. National Archives and Administration, Record Group 59, Decimal File 1945-49, Box 5356.

-----, "El Siglo", 16-1-1945. National Archives and Administration, Record Group 59, Decimal File 1945-49, Box 5355.

Gould, Alan J. Roundup Circular no. 21, 28-12-1943. Associated Press Corporate Archives, Collections Online: https://link.gale.com/apps/doc/ AOFEGI313067259.

Ministerio del Interior, Decreto $N^{o} 5.815,20-11-1940$. Archivo Nacional de la Administración, fondo Ministerio del Interior, vol. 10.158.

-----, Decreto $N^{o}$ 1.548, 18-3-1943. Archivo Nacional de la Administración, fondo Ministerio del Interior, vol. 10.911.

-----, Decreto $N^{\circ}$ 547, 26-1-1943. Archivo Nacional de la Administración, fondo

Ministerio del Interior, vol. 10.873.

-----, Decreto $N^{o} 548,26-1-1943$. Archivo Nacional de la Administración, fondo

Ministerio del Interior, vol. 10.873.

-----, Decreto $N^{\circ}$ 549, 26-1-1943. Archivo Nacional de la Administración, fondo

Ministerio del Interior, vol. 10.873.

-----,LeyN $N^{\circ} 7.401,31-12-1942:$ https://www.leychile.cl/Navegar?idNorma=25544

The Associated Press. The Associated Press Directory, 1940. Associated Press

Corporate Archives, Collections Online: https://link.gale.com/apps/doc/ AOMNGU978394553/ 